\title{
O instante do prazer e da alegria: um caminho para a ressurreição dos corpos em Rubem Alves
}

\author{
Douglas Rodrigues da Conceição*
}

\section{Resumo}

Este artigo ocupa-se com o pensamento de Rubem Alves no livro Variações sobre o prazer, que foi publicado em 2011. Apesar das críticas à religião, o nosso principal objetivo, neste texto, é apresentar a maneira com a qual o teólogo e psicanalista a recupera na arquitetura da referida obra.

Palavras-chave: Prazer. Alegria. Corpo. Babette. Ressurreição.

\section{The moment of pleasure and joy: a way for} the resurrection of the bodies in Rubem Alves

\section{Abstract \\ This present article deals with the thought of Rubem Alves in the book Variações sobre o prazer, which was published in 2011. Despite the criticism about religion, our main objective in this text is to present the way in which the theologian and psychoanalyst recovers it in the architecture of said work. \\ Keywords: Pleasure. Joy. Body. Babette. Resurrection. \\ El momento de placer y alegría: un camino para la resurrec- ción de los cuerpos en Rubem Alves}

\section{Resumen}

Este artículo aborda el pensamiento de Rubem Alves en el libro Variações sobre o prazer, que se publicó en 2011. A pesar de las críticas sobre la religión, nuestro principal objetivo de este texto es presentar la forma en la que el teólogo y psicoanalista lo recupera en la arquitectura de dicho trabajo.

Palabras clave: El placer. La alegría. Cuerpo. Babette. La resurrección.

* Doutor em Ciências da Religião, UMESP. Realizou estágio de pós-doutorado em Literatura, Université Paris X. Professor Adjunto IV da Universidade do Estado do Pará. E-mail: abismos@gmail.com 


\title{
1. Rubem Alves, o "Livro Sem Fim" e o Cair da Noite
}

\author{
"Para o desejo do meu coração, o mar é uma gota..." \\ - Adélia Prado
}

$\mathrm{O}$ artigo em questão ocupa-se essencialmente com o pensamento de Rubem Alves na obra Variaçoes sobre o prazer, ${ }^{1}$ que foi publicada em 2011. Problematizando questões de ordem autobiográfica e existencial, interpelando as representações tradicionais da razão como figuram no âmbito da filosofia, da ciência e da educação e criticando a religião, Rubem Alves procura, sobretudo, nas linguagens artísticas e nas noções de prazer e de alegria uma via alternativa para a compreensão do humano e seu sentido.

Há em Variações sobre o prazer uma clara relação dos problemas tratados na obra com determinadas experiências que derivam da própria vida de Rubem Alves. No prefácio do livro, o psicanalista narra o drama que o levara a publicar o que chamou de "um livro sem fim". Lembrando-se de um "exercício espiritual" ou "joguinho de "faz de conta", que foi sugerido por um dos amigos que com ele havia tempos vinha ler poesias e cujo objetivo seria pensar de que forma viveriam se soubessem que pela frente nada mais haveria senão um ano de vida, Rubem Alves concluiu que a consciência da morte trazia consigo o que chamou de lucidez. A questão exposta pelo amigo foi a seguinte: "Vamos fazer de conta que sabemos que temos apenas um ano a mais de vida. Como é que viveremos sabendo que o tempo é curto [...]" (ALVES, 2014, p. 8). Em 19 de julho 2014, Rubem Alves nos deixaria.

A decisão de publicar o livro, que considerava ser um projeto fracassado, nasce da constatação de que a vida nunca acaba e, portanto, o próprio livro se pareceria com a própria substância da vida. O ter-consciência-do-fim é o que apontaria ao ser humano o inacabamento ao qual o próprio existir está condenado. Variações sobre o pražer metaforiza então a própria determinação da vida: "[...] nunca é terminada. Ela termina sempre sem que tenhamos escrito o último capítulo" (ALVES, 2011, p. 13). É desse pressuposto que Rubem Alves decide "brincar" com "a ideia de publicar o livro do jeito que estava, não terminado" (ALVES, 2014, p. 13). É com o crepúsculo que compreendeu que o prazer e a alegria, objetos do existir, estão presentes no caminho que se faz

Conforme informações do Instituto Rubem Alves. Disponível em: http://www.institutorubemalves.org.br/acervo/acervo/ Acesso em $10 \mathrm{dez}$. 2017. Para este artigo, utilizaremos a segunda edição, que foi publicada em 2014. 
e não no final dele. "Pensei que meu livro poderia ser como uma caminhada que não chegou ao fim - caminhada que parou no meio do caminho. E assim resolvi: vou publicar um livro sem fim" (ALVES, 2011, p. 14).

Sem recorrer a qualquer arranjo de natureza soteriológica, a pergunta "o que fazer do tempo que resta?" é uma das provocações que Rubem Alves faz questão de expor em Variações sobre o prazer. Uma vez que "enfermos de morte" todos nós estamos, "sem que o saibamos", outra coisa não nos restaria senão afirmar a vida como um dogma inquestionável e com um grito de sim na direção dela (cf. ALVES, 2014, p. 10). Portanto, pensar o prazer e a alegria como dimensões indeléveis da condição humana, ou seja, o destino único para o ser humano, o que me parece um dos projetos de Variações sobre o prazer, é antes admitir que "vivemos para o prazer" (ALVES, 2014, p. 84).

É no anoitecer que Rubem Alves procurou juntar alguns fragmentos da matéria com a qual teceu sua vida. Essa matéria é feita de eventos dotados de pleno sentido - basta lembrar as leituras de poesia que realizava com amigos - mas também das companhias que estiveram ao seu lado, quais sejam, a dos poetas, a dos escritores, a dos pensadores, a dos compositores, a dos cineastas. Tudo isso é revisitado por Rubem Alves. A velhice lhe aparece como um momento de iluminação. "Mudei. Mudaram-se os meus olhos. Passei a ver o mundo de forma diferente, banhado por uma luz crepuscular" (ALVES, 2014, p. 47). Esse olhar retrospectivo, que privilegia o homem que se confronta com o crepúsculo e que procura ordenar e compreender o que foi, é um traço distintivo de quem coloca a si mesmo sob exame. Trata-se de uma espécie de recapitulação parcial de um arco existencial: "Não sei se foi a velhice que abriu os meus olhos ou se ela, a velhice, simplesmente me deu coragem para dizer o que eu sempre vira e não dissera, por medo" (ALVES, 2014, p. 47). É desse lugar, onde a noite é já presente, que Rubem Alves encontrará no prazer e na alegria os fundamentos de uma vida autenticamente humana.

\section{A educação pelo corpo e os rastros negativos da religião}

Seria quase impossível pensar as noções de prazer e alegria, ${ }^{2}$ que aparecem em Variações sobre o prazer, sem pensar o protagonismo do corpo. Fabiano Veliq recupera uma importante entrevista concedida pelo autor de O enigma da religião a Luis Vázquez Buenfil, a partir da qual procura apontar a

2 Para consultar as apropriações que Rubem Alves faz das noções de prazer e alegria, veja o capítulo 8, "Variações sobre o prazer" (cf. ALVES, Rubem. Variações sobre o praz̧er, 2. ed. São Paulo: Planeta, 2004, p. 83-91). 
emergência do corpo como uma questão fulcral dentro do seu pensamento. A seguir, reproduzo um fragmento dessa entrevista:

Uma questão que posteriormente ficou, ou tornou-se importante para mim, foi a questão do corpo. Compreendi que todas as lutas que se travam têm a única finalidade de fazer com que o corpo seja feliz. Não há nada absolutamente mais importante no mundo do que o corpo. Se nós fazemos a revolução, a única finalidade da revolução é permitir que os corpos não tenham medo, que possam dormir em paz, que possam trabalhar em paz, que possam criar o amor, que possam ter seus filhos. Que possam viver o futuro sem medo, sem angústias. Então, meu pensamento sobre Deus transformou-se realmente em um pensamento sobre a libertação do corpo [...] (BUENFIL apud VELIQ, 2014, p. 189).

Rubem Alves nos faz enxergar que a reabilitação do corpo no seu pensamento tem a ver com a pouca atenção que a filosofia (não a de Nietzsche, a quem dedica a segunda variação) e a ciência tradicionais e suas respectivas formas de razão conferiram a ele, mas também por ele (o corpo) ter se tornado uma das principais vítimas da violência promovida pela religião. Rubem Alves "aceita" essa dissintonia entre as formas de representação da razão e o corpo, isso porque compreende que as linguagens usadas por tais mecanismos de conhecimento, como a ciência, a técnica e a própria filosofia, não são capazes de serem compreendidas pelo corpo. Afirma Rubem Alves: "Procuro a filosofia do corpo. Não procuro uma filosofia sobre o corpo. Filosofia sobre o corpo são os pensamentos que os filósofos pensam. Filosofia do corpo são os saberes que o corpo sabe sem saber. É sapientia. É a voz dos poetas, dos artistas, das crianças..." (ALVES, 2014, p. 80).

Rubem Alves sabe que as principais formas de interdição e de desprezo pelo corpo foram criadas pela religião, muito embora, paradoxalmente, o próprio corpo tenha certo protagonismo no interior da espiritualidade cristã quando pensado a partir do dogma da ressurreição. ${ }^{3}$ Em que pese tal consideração, a história do corpo no ambiente da tradição cristã é negativa. Dela derivam as imagens de um corpo cindido de si mesmo, longe do que o realiza e que traz consigo a herança das sucessivas formas de mortificação a que foi submetido e, por isso, precisa reconciliar-se, o que significaria estabelecer um reencontro com o prazer e com a alegria que dele depende

3 Sobre a afirmação da importância do corpo no cristianismo, cf. Refoulé, F. Immortalité de l'âme et résurrection de la chair, p. 43. 
e que nele se manifesta. Rubem Alves (2014, p. 84) admite inclusive que o objetivo da educação, como instrumento de descoberta e conhecimento, seria o de "aumentar as possibilidades de prazer e alegria", isto é, fazer que o corpo e não só a razão conduza o humano ao que tem de último. Portanto, Rubem Alves postula outras formas de orientação humana que não estejam tuteladas à razão que mecaniza e instrumentaliza, nem à religião que anula e enrijece. Ele contesta a religião porque, historicamente, entre outras atrocidades, transformou em escândalo "a bondade do prazer". ${ }^{4}$ Prazer só pode existir no e para o corpo. Por isso, considera a existência de saberes do corpo como elemento fundamental para uma compreensão mais precisa de nós mesmos, posto que sem eles (tais saberes) a vida "há muito tempo já teria desaparecido" (ALVES, 2014, p. 75). Essa unidade inteligente, que é o corpo, "sabe sem precisar saber. O corpo é sábio. O corpo é educador por graça, de nascimento. Não precisa de aulas de pedagogia" (ALVES, 2014, p. 78).

É desse ponto que Rubem Alves, sendo crítico da religião, mas sem ter se desfeito totalmente dela, ${ }^{5}$ e sendo crítico da educação, embora dela tenha vivido e nela se aposentado, ${ }^{6}$ alia-se à poesia, à música e à culinária como vias mais autênticas de condução ao prazer de viver, à alegria e à afirmação da vida. ${ }^{7}$ É dessa perspectiva que Rubem Alves critica os poderes nocivos e instrumentalizadores da religião, da filosofia acadêmica, da universidade e da ciência. Se Variações sobre o prazer é antes um livro que procura afirmar o amor pela alegria e pelo prazer, e não o desprezo de ambos, isso explicaria em parte o porquê de Rubem Alves iniciar suas próprias variações estampando a censura que a espiritualidade ocidental nutriu em relação ao próprio prazer.

Essa imagem que Rubem Alves decalca sobre espiritualidade que deriva das formas religiosas hegemônicas do ocidente pode ser uma boa pista para se chegar a uma das quatro variações ensaiadas no livro. Refiro-me especificamente à quarta variação, a culinária, na qual Rubem Alves dialoga com o belo filme dinamarquês $A$ festa de Babette $e^{8}$ e também com o filme Como água para chocolate.

4 Expressão que Rubem Alves cunha de Octávio Paz (cf. ALVES, Rubem, Variações sobre o prazer, p. 83).

5 "Uns acham que não acredito em Deus. Como não acreditar em Deus se há jardins?” (cf. ALVES, Rubem, Variações sobre o prazer, p. 11).

6 "Vivi muito tempo no mundo acadêmico. O mundo acadêmico é perigoso. Dá medo" (cf. ALVES, Rubem, Variações sobre o prazer, p. 47).

7 Rubem Alves consagra uma secção do livro ao que chama de educação dos sentidos (cf. ALVES, Rubem, Variações sobre o prazer, p. 173).

8 O filme $A$ festa de Babette, 1987, é uma adaptação cinematográfica feita a partir de um conto 
Antes de chegar em Babette, Rubem Alves revisita Santo Agostinho, Nietzsche e Marx. Transforma-os em personagens das demais variações de sua sinfonia. Mas é $A$ festa de Babette o que mais me interessa aqui.

O que seria preciso manter em perspectiva é que as formas de exaltação da vida que Rubens Alves apresenta em Variações sobre o praz̧er só podem encontrar amparo num tipo de humano que orienta sua existência para o amor ao prazer e à alegria. Nada além! O instrumento que cada um deve ter consigo não pode ser outro senão a "flauta de Dionísio" (ALVES, 2014, p. 113). É o corpo que é posto em cena. Prazer, alegria, música, culinária e poesia só podem existir no e para o corpo, porque "O prazer tem a ver com o corpo, e só" (ALVES, 2014, p. 118).

\section{Babette: "a Sacerdotisa de Eros"}

Na primeira variação, Rubem Alves (2014, p. 96) retoma a crítica à tradição cristã, e a acusa de se opor e temer o prazer. Temos aqui um rastro para compreender sua admiração por Nietzsche e a invocação de Dionísio na segunda variação: "toco a flauta de Dionísio para acordar o instinto" (ALVES, 2014, p. 116). Nietzsche é reconhecidamente o filósofo que anuncia a chamada morte de Deus. ${ }^{9}$ Do pensamento do filósofo alemão deduz-se uma forma de vitalismo que rejeita não só as expressões metafísicas do mundo, mas também uma moral ancorada na tradição judaico-cristã ocidental. No Ecce Homo, obra que Rubem Alves revisita incessantemente, Nietzsche (2008, p. 61) afirma: “[...] - Quem não só compreende a palavra 'dionisíaco', mas se compreende nela, não necessita de refutação de Platão, do cristianismo ou de Schopenhauer - fareja a decomposição...” Creio que é sob essa ótica, e provavelmente existem outras que não enxergo, que Rubem Alves debruça-se sobre o filme A festa de Babette. A personagem Babette Hersant, uma chef de cozinha e protagonista do filme que leva seu nome, é para Rubem Alves a representação da sábia que possui as chaves do corpo. Essa representação se opõe à do homem da ciência e à do filósofo, posto que as últimas são para Rubem Alves míopes em relação ao que substancialmente define o humano. A filosofia e a ciência usam uma linguagem que o corpo não entende (ALVES, 2014, p. 175). Babette não! Ela está aliada a uma expressão artística, a uma

extraído da obra da escritora dinamarquesa Karen Blixen. A obra fílmica foi dirigida por Gabriel Axel.

9 Aforismo 125 da obra A gaia ciência (cf. NIETZSCHE. A gaia ciência. São Paulo: Companhia das Letras, 2001, p. 147-148). 

um caminho para a ressurreição dos corpos em Rubem Alves

linguagem que se funde ao prazer e à alegria: a culinária. ${ }^{10}$ Babette promove uma verdadeira (re)educação pelo corpo.

O filme retrata um pequeno vilarejo dinamarquês, seus moradores e sua atmosfera religiosa de origem luterana. Fugindo de uma perseguição política em seu país, a francesa Babette chega à vida de Martine e Filippa, filhas do falecido pastor local, sob recomendação do cantor lírico Achilles Papin, que passara pelo vilarejo de Jutlândia muitos anos antes. A vida de Babette, desde então, é consagrada à casa e aos cuidados das solitárias e religiosas irmãs.

A influência do filme dinamarquês sobre o Rubem Alves de Variações sobre o prazer é nítida. Justo reconhecimento do filme faz ele na quarta variação composta para a sua obra. O amor à alegria e ao prazer são expressões de um vitalismo que o psicanalista enxerga na cozinheira e no seu grande talento artístico. Apesar de ter enterrados todos os seus mortos em sua cidade natal, Babette espelha esse ser humano que com um grito declara o "[...] mais exaltadoexuberante Sim à vida” (cf. NIETZSCHE, 2008, p. 61). Sobre Babette não imperam os poderes que degeneram o existir. Ela tão somente afirma a existência como se apresenta. Babette encarna um tipo de amor à vida que poderia muito bem ser entendido como aquele que Nietzsche chamou de amor fati.

[...] Quero cada vez mais aprender a ver como belo aquilo que é necessário nas coisas: - assim me tornarei um daqueles que fazem belas as coisas. Amor fati [amor ao destino] - seja este, doravante, o meu amor! Não quero fazer guerra ao que é feio. Não quero acusar, não quero nem mesmo acusar os acusadores. Que a minha única negação seja desviar o olhar! E, tudo somado e em suma: quer ser, algum dia, apenas alguém que diz Sim! (NIETZSCHE, 2001, p. 187-188).

E ainda: "Minha fórmula para a grandeza no homem é amor fati: nada querer diferente, seja para trás, seja para frente, seja em toda eternidade. Não apenas suportar o necessário, menos ainda ocultá-lo" (NIETZSCHE, 2008, p. 49). Babette não cede ao peso das perdas, à dor do sofrimento e não se resigna frente à ida que passa a ter em Jutlândia. Ela, ao contrário, afirma o destino que desponta, afirma o tempo que resta dizendo sim à vida. Babette sabe ainda que a vida deve ser afirmada, apesar de tudo, e preenchida com prazer e alegria: ambos são a dimensão final da arte que ela conhece e domina: a culinária (ALVES, 2014, p. 129). Essa autoafirmação da vida, que poderíamos

10 Diz Rubem Alves: "Perguntem à Babette qual é o fim da culinária... Ela responderá: 'o prazer, a alegria!"” (cf. ALVES, Rubem, Variações sobre o pražer, p. 129). 
chamar de vitalidade, ${ }^{11}$ supera o sentimento do não-ser. A vida de Babette expressa certa intransitividade diante do existir.

\section{O Banquete: uma variação para o prazer}

O banquete de Babette em nada se assemelha ao mais conhecido banquete da história do pensamento ocidental: o de Platão. Ao contrário do banquete de Platão, o banquete de Babette mira os corpos e os efeitos da boa comida sobre eles. Enquanto o banquete de Babette mira o amor pela alegria e pelo prazer - tanto que gastou tudo o que o tinha em nome deles - o de Platão se obceca por uma verdade inalcançável sobre Eros. Babette não precisa se perguntar o que é o amor. Ela o sabe. No banquete de Babette só há vez para o corpo e não para o logos. É através do corpo que os convivas de Martine e Filippa se exprimem. Os corpos "enfermos de morte" das personagens do filme - embora mantivessem diante de si a promessa de um paraíso celeste acabam cedendo ao paraíso terrestre oferecido pelo feitiço que sai das mãos da ex chef do Café Anglais de Paris, até porque o corpo, como sublinha Rubem Alves, "é único lugar onde a magia é verdadeira", porque só nele "o puro pensamento é capaz de mover a matéria" (ALVES, 2014, p. 144).

A ideia do banquete surge quando Martine e Filippa decidem comemorar o que seria o aniversário de 100 anos do pastor do vilarejo. Babette acabara de receber a notícia de que seu bilhete de loteria, há anos renovado por um amigo de Paris, havia sido premiado, o que a levou a oferecer às irmãs a organização da festa. Babette sabia que a preparação desse jantar - como os que servia no mítico Café Anglais - lhe daria a chance de rever a vida que viveu dentro da vida que tem no presente.

Com a chegada das iguarias para a preparação do "jantar francês", as pessoas do vilarejo, em toda sua rusticidade, não compreendiam a ebulição sensorial provocada pelos ingredientes em seus corpos. Martina e Filippa se reúnem com os fiéis da seita fundada pelo pastor e pai das irmãs para lhes comunicar que no lugar de uma singela homenagem ao falecido religioso consentiram, inocentemente, a organização de um banquete satânico, o que poderia pôr em risco o paraíso celeste de todos. Decidem ir ao banquete, todavia, nenhuma palavra sobre ele sairia de suas bocas. A sofisticação dos ingredientes do banquete de Babette em nada se parecia à tradicional sopa de pão de cerveja, prato do cotidiano dos habitantes da pequena aldeia. $\mathrm{O}$

11 Cf. Conceição, Douglas Rodrigues da. Teologias e literaturas 3. São Paulo: Fonte Editorial, 2013, p. 146. 
banquete contaria ainda com a presença de um ilustre conviva: o então general Lorens Löwenhielm, que na sua juventude havia se enamorado por Martine. O oficial enxergara cedo o fracasso ao qual o seu amor por ela estava fadado, isso em razão da austera educação religiosa recebida.

Iniciado o banquete, o general é o único à mesa que reconhece, no nível culinário, o que se passa ali. Seu corpo rumina as reminiscências de sabores já experimentados. O sabor se transforma de fato na prova dos nove para o corpo (ALVES, 2014, p. 144). Löwenhielm, em razão da vitória de uma competição de equitação em Paris, fora agraciado com um jantar no Café Anglais. É dessa magnífica experiência que seu corpo faz questão de lembrar.

\section{Uma breve semiótica do corpo}

Embora crítico da religião, Rubem Alves não se desfaz completamente dela na arquitetura do seu pensamento. Em Variações sobre o prazerer, a importância do corpo, frente a uma nova perspectiva para educação e também diante de uma possível reorientação epistemológica das ciências e da filosofia, nos dá uma nítida pista da recuperação que ele promove da dimensão simbólico-metafórica da ressurreição do corpo a partir da tradição cristã. Admitir a retomada da ressurreição do corpo torna-se uma importante chave para se entender a edificação teórico-artística do pensamento alvesiano em Variações sobre o prazer. A interlocução que Rubem Alves faz com o filme de Gabriel Axel representa bem o que acabamos de afirmar.

A vida dos habitantes no vilarejo era completamente opaca até a chegada de Babette. Durante o período em que se ausentou de Jutlândia para a compra dos ingredientes do banquete, os desvalidos assistidos pelas irmãs, nas ações de caridade realizadas por elas, sentem a ausência da cozinheira. Esses corpos, antes alimentados apenas para se manterem vivos biologicamente, ao experimentarem a comida de Babette, saboreiam também prazer e alegria. Numa linguagem tillichiana, provam o infinito no finito. As reações alquímicas produzidas pela comida preparada por Babette fazem os corpos "enfermos de morte" se elevarem da sepultura do tempo. É por isso que Rubem Alves (2014, p. 162) chega a dizer que o preparo de uma comida é um ritual mágico e tal magia faz que os corpos abram-se à violação provocada pelo prazer e pela alegria.

A vida resignada do vilarejo é sobremaneira sacudida pela força da arte que Babette domina: a culinária. Babette domina o fogo! As reações alquímicas que sua comida provoca nos insepultos habitantes torna crível e humanamente possível a ideia de ressurreição do corpo. Um corpo ressurreto seria então 
um corpo conciliado com o prazer e com a alegria. Tal dimensão última (o prazer e a alegria), assim Rubem Alves compreende, converte-se num novo referencial teleológico da existência.

Com exceção do general Lorens Löwenhielm, os convivas de Martine e Filippa trajam preto, cor que evoca uma atmosfera fúnebre para o banquete. Um retrato do falecido líder espiritual, afixado numa saleta da casa das irmãs, sugere a manutenção dos rigorosos preceitos éticos e morais difundidos pela seita fundada por ele. Já sentados à mesa, uma oração de blindagem espiritual contra os poderes satânicos do que seria servido no banquete é realizada. À medida que a comida e a bebida passam a interagir com os corpos dos convivas, percebe-se claramente o foco das lentes nas reações "alquímicas" que desses corpos emergem. Gestos e expressões faciais que exprimem intenso prazer são inevitáveis, muito embora os irmãos e irmãs de fé estivessem convencidos de que o sentido do paladar deveria ser esquecido. Aqui entra em cena o que Rubem Alves (2014, p. 152) chama de "violência da culinária", porque ela obriga a natureza indiferente (a comida) a fazer amor com os corpos. Aos poucos os convivas vão sendo tomados pelo prazer e pela alegria. Eros, então, assume as rédeas do banquete. Pelas mãos de Babette, "tudo é feito para dar prazer" (ALVES, 2014, p. 153). Recentemente, lembrando-se da ex chef do Café Anglais, o pontífice Francisco sublinhou que "as alegrias mais intensas da vida" emergem, como que numa antecipação do céu, "quando se pode provocar a felicidade dos outros" (PAPA FRANCISCO, 2016, p. 107). Em sua exortação o papa Francisco já não mirava somente a alegria que possui os corpos dos convivas, mas também a de Babette, que brota do senso de gratidão pelas duas irmãs e do seu amor por elas e pela arte da cozinha. Babette estaria, portanto, possuída pelo que poderíamos chamar de Amoris Laetitia.

Tomados pelas delícias terrenas, o bomo religiosus cede lugar ao bomo vitalis. ${ }^{12}$ É assumindo essa condição (a de homo vitalis) que os convivas, inebriados pela sedução que o banquete exerce sobre seus corpos, experimentaram, quiçá pela primeira vez, aquilo que Norman Brown (1985, p. 307) chama de instinto de vida. Rubem descreve assim o efeito do banquete de Babette sobre os comensais:

[...] Sem uma palavra, a comida de Babette fez seu trabalho. Os convidados, velhos endurecidos que a inveja tornara amargos e ácidos, suspeitaram que

12 Cf. Conceição, Douglas Rodrigues da. Teologias e literaturas 3. São Paulo: Fonte Editorial, 2013, p. $155-167$. 

um caminho para a ressurreição dos corpos em Rubem Alves

algum ritual bruxo estava sendo preparado naquele banquete, e trataram de se precaver: juraram tornar insensíveis o seu paladar e o seu olfato. Sabiam que as potências mágicas penetram diretamente no corpo pelos canais do prazer, onde nem ideias, nem palavras conseguem penetrar. Inutilmente. O prazer faz o seu trabalho de forma irresistível e deliciosa. Logo, logo os corpos encruados ficaram tenros/ternos. Podiam agora ser comidos. E os olhos passaram a ver em harmonia com o ser. Ao final, estavam todos transformados em crianças... E experimentaram, por um momentos, a alegria do paraíso: brincaram (ALVES, 2014, p. 159).

Os enquadramentos das faces das personagens, cada vez mais frequentes durante o desenrolar do banquete, procuram focalizar os efeitos mágicos da comida e da bebida. Os corpos, antes marcados pelas amarras éticas da religião e pelo peso do tempo, cedem aos acordes ditirâmbicos do "verdadeiro jantar francês" oferecido por Babette, ou seja: os corpos experimentam o que Rubem Alves chama de "efêmera epifania do Paraíso" (ALVES, 2014, p. 87). A isso eu chamaria de transcendência na imanência. ${ }^{13}$

Durante o banquete, os convidados de Martine e Filippa experimentaram um autêntico instante extraordinário, ${ }^{14}$ como diria Nietzsche. A duração do banquete permitiu que aos pés do Vesúvio os comensais construíssem casas e nelas habitassem, ainda que por um instante. Deliciosamente, correram o risco de perder o céu sob a possessão do prazer e da alegria. A espera de uma vida eterna, para melhor explicitar seu conteúdo cristão, ficou em suspenso durante o memorável festim.

\section{Considerações finais}

Visitei Babette, a quem Rubem Alves dedica grandiosamente sua quarta variação. Mas seria oportuno lembrar que na primeira, segunda e terceira variações são Agostinho, Nietzsche e Marx os seus interlocutores, respectivamente. Para o diálogo com Nietzsche, encontramos imediatas justificativas. Nietzsche o seduz por sua antimetafísica, e o faz ouvir "a flauta de Dionísio" e lhe apresenta o que chama de amor fati, por exemplo. Mas o mesmo não acontece quando penso em Agostinho e Marx. Fiquei com a impressão de que Rubem Alves queria fazer "justiça" ao santo da igreja e ao pai do

\footnotetext{
13 Cf. Ibid.

14 Expressão retomada da tradução do aforismo 341, da obra A gaia ciência de Nietzsche, feita por Marco Antônio Casanova (cf. CASANOVA, Marco Antônio. O instante extraordinário. Rio de Janeiro: Forense Universitária, 2003).
} 
comunismo. Rubem Alves nos apresenta um Agostinho que, ao distinguir dois tipos de coisas em A doutrina cristã, parece compassivo tanto à insaciável sede humana pelas coisas que existem para "serem fruídas" (SANTO AGOSTINHO, 2002, p. 43), ou seja, aquelas que se possuídas provocam prazer, quanto ao senso humano que encontra no uso das coisas que existem para "serem utilizadas" (SANTO AGOSTINHO, 2002, p. 43) um caminho mais curto para o alcance das primeiras. Eis aí uma conciliação perfeita entre as coisas que estão na "Feira das Utilidades" (ALVES, 2014, p. 94) e na "Feira da Fruição" (ALVES, 2014, p. 98). A viola e os demais instrumentos, por exemplo, pertenceriam à "Feira das Utilidades", porque seriam apenas uma "possibilidade de música" (ALVES, 2014, p. 97), mas uma sonata, como as que fez Mozart, estaria na "Feira da Fruição", justamente porque ao ouvi-la encontraríamos o prazer. Creio, todavia, que Rubem Alves esqueceu de dizer que se a antropologia de Agostinho reconhece que as criaturas humanas gozam pela posse daquilo que desejam, ela reconhece também que o ser humano não pode se entregar à fruição das coisas sob pena de se desviar da peregrinação para Deus. Exorta o bispo de Hipona: "Se queremos voltar à Pátria, havemos de usar deste mundo, mas não fruirmos dele" (SANTO AGOSTINHO, 2002, p. 45). Eis um paradoxo! Confesso não conseguir enxergar com a mesma nitidez de Rubem Alves o convite que Agostinho nos faz ao prazer, à alegria e à felicidade.

Ao trazer Marx para o diálogo, Rubem Alves ensaia uma crítica ao capitalismo, incluindo nela a questão do corpo e do prazer. O Marx com o qual interage é o da crítica ao trabalho alienado, que só retroalimenta "a Feira das Utilidades" e que impede os sujeitos de perceberem o prazer como uma finalidade possível para si mesmos. Na companhia de Marx, no quadro pintado por Rubem Alves não há prazer na perspectiva. Se corpo e prazer são faces da moeda, aos corpos não caberia apenas a condição de máquinas produtivas. Pode ser que o meu olhar esteja equivocado, mas Rubem Alves, no fundo, reconhece que a lógica capitalista, desde muito cedo, deu a devida atenção ao prazer. A lógica capitalista não se esgota na maximização de lucros pela exploração do trabalho realizado pelos corpos. Ela sabe que corpos produzem, e por isso os explora, mas sabe também que eles desejam e consomem. Isto explica muito parcialmente o verdadeiro fascínio que as mercadorias (mas não só elas) exercem sobre as massas de consumidores cada vez mais numerosas. É nesse ponto que Rubem Alves faz entrar em cena outra forma de desprezo pelo corpo, e ele tem razão. Tal forma de desprezo se realiza quando o capitalismo reduz o corpo a certo tipo de instrumento condicionado não só à 

um caminho para a ressurreição dos corpos em Rubem Alves

produção, mas também ao consumo de todo gênero de mercadoria. É Marx, pois, quem lhe faz enxergar esse quadro. Em minha ótica, o que Rubem Alves critica sob o crivo de Marx é o fato de o capitalismo reduzir a possibilidade do prazer à lógica do consumo. "O prazer não é dado automaticamente pelo ter” (ALVES, 2014, p. 130), ou seja, a lógica do consumo não determina tudo. Mas os corpos treinados para a produção e o consumo perdem a capacidade de sentir "certo prazer inútil", aquele que nada representa economicamente. A alternativa que ele encontra ao poder de sedução do jogo do capitalismo é o que chama de "educação dos sentidos para os prazeres inúteis" (ALVES, 2014, p. 131), porque o capitalismo - se bem compreendo o que Rubem Alves quer dizer - não se preocupa com o que é economicamente insignificante. A transformação dos corpos em ferramentas (os corpos úteis) e o abandono da "educação dos sentidos para os prazeres inúteis", cuja responsabilidade ele tributa à educação, servem como solos férteis para o cultivo da lógica capitalista. Apenas a título de lembrança, não podemos esquecer que não era o mundo do capitalismo que o poeta Vladimir Maïakovski tinha diante dos seus olhos quando atentou contra a própria vida.

Difícil seria admitir certa novidade às críticas que Rubem Alves desfere sobre a religião. Criticar a religião, após Feuerbach, Nietzsche, Marx e Freud não é tarefa simples. Certo é que seu particular criticismo - permitam-me o uso quase arbitrário do termo - não recai somente sobre ela. A ciência, a educação e a universidade são também postas em xeque em Variações sobre o prazer. Se é possível uma forma de "redenção" para o ser humano esta não pode derivar senão da relação desse humano com a poesia, a literatura, a música e com a culinária, que são expressões artísticas e de conhecimento que antes pressupõem o protagonismo do corpo. Foi por esse caminho, por exemplo, que encontramos a importância que o filme de Gabriel Axel e a dimensão simbólica de sua personagem principal emprestam ao pensamento de Rubem Alves em Variações sobre o prazerer.

Conhecendo sua vinculação com a psicanálise e admitindo que a noção de prazer foi importantíssima para Freud, é de se estranhar que Rubem Alves não tenha dialogado explicitamente com o autor de Além do princípio do prazer. Aliás, Freud sequer aparece na bibliografia de Variações sobre o prazer. O que seria possível dizer é que Rubem Alves retoma o prazer e o conjuga com a alegria como possíveis chaves decifradoras do autenticamente humano e do seu destino. Prazer e alegria em Variações sobre o praz̧er assumem praticamente o sentido do ser humano. 
A despeito das críticas à religião, que estão espalhadas em Variações sobre o prazer, Rubem Alves, incognitamente, reabilita a doutrina da ressurreição em seu pensamento. Que categoria poderia melhor explicar o fenômeno físico-espiritual (alquímico segundo Rubem Alves) que sobreveio aos "velhos endurecidos" e "enfermos de morte" que se deleitaram com o banquete de Babette? 'Tal ressurreição dos corpos, todavia, não pode ser pensada fora do tempo, fora do instante. Pensar a ressurreição adornada ou acompanhada da ideia de eternidade só seria possível se fosse comparada com a necessidade que temos de ouvir novamente e talvez incessantemente uma composição de Chopin ou mesmo compará-la ao eterno sim que os convivas de Martine e Filippa certamente pronunciariam na direção de sua eterna fome, caso a eles fosse dada a oportunidade de se sentar uma vez mais à mesa de Babette, antes que a vela se apague.

\section{Referências}

A FESTA DE BABETTE. Direção: Gabriel Axel Produção. Dinamarca, 1987.

ALVES, Rubem. Variações sobre o prazer, 2. ed. São Paulo: Planeta, 2014.

. O enigma da religião, 4. ed. Campinas: Papirus, 1988.

CASANOVA, Marco Antônio. O instante extraordinário. Rio de Janeiro: Forense Universitária, 2003.

CONCEIÇÃO, Douglas Rodrigues da. Teologias e literaturas 3. São Paulo: Fonte Editorial, 2013.

NIETZSCHE. A gaia ciência. São Paulo: Companhia das Letras, 2001.

. Ecce Homo. São Paulo: Companhia das Letras, 2008.

PAPA FRANCISCO. Exortação apostólica pós-sinodal Amoris Laetitia. São Paulo: Paulinas, 2016.

REFOULÉ, F. Immortalité de l'âme et résurrection de la chair, Revue de l'histoire des religions, n. 1, p. 11-52, 1963.

SANTO AGOSTINHO. A doutrina Cristã. São Paulo: Paulus, 2002.

VELIQ, Fabiano. Dizer e viver a esperança. Aspectos sobre linguagem e religião no pensamento de Rubem Alves. Reflexus - Revista de Teologia e Ciências das Religiões, Ano VIII, n. 2, p. 169-197, 2014.

Submetido em: 9-3-2017

Aceito em: 18-7-2017 